\title{
Adsorption of heavy metal ion from aqueous single metal solution by chemically modified sugarcane bagasse
}

\author{
Osvaldo Karnitz Jr. ${ }^{a}$, Leandro Vinicius Alves Gurgel ${ }^{a}$, Júlio César Perin de Melo ${ }^{\text {a }}$, \\ Vagner Roberto Botaro a, Tânia Márcia Sacramento Melo a, \\ Rossimiriam Pereira de Freitas Gil ${ }^{\text {b }}$, Laurent Frédéric Gil ${ }^{\text {a,* }}$ \\ ${ }^{a}$ Departamento de Química, Instituto de Ciências Exatas e Biológicas, Universidade Federal de Ouro Preto, 35400-000 Ouro Preto, \\ Minas Gerais, Brazil \\ b Departamento de Química, Instituto de Ciências Exatas, Universidade Federal de Minas Gerais, 31270-901 Belo Horizonte, \\ Minas Gerais, Brazil
}

Received 22 November 2005; received in revised form 28 April 2006; accepted 2 May 2006 Available online 14 July 2006

\begin{abstract}
This work describes the preparation of new chelating materials derived from sugarcane bagasse for adsorption of heavy metal ions in aqueous solution. The first part of this report deals with the chemical modification of sugarcane bagasse with succinic anhydride. The carboxylic acid functions introduced into the material were used to anchor polyamines, which resulted in two yet unpublished modified sugarcane bagasse materials. The obtained materials were characterized by elemental analysis and infrared spectroscopy (IR). The second part of this reports features the comparative evaluation of the adsorption capacity of the modified sugarcane bagasse materials for $\mathrm{Cu}^{2+}, \mathrm{Cd}^{2+}$, and $\mathrm{Pb}^{2+}$ ions in aqueous single metal solution by classical titration. Adsorption isotherms were studied by the Freundlich and Langmuir models.

(C) 2006 Elsevier Ltd. All rights reserved.
\end{abstract}

Keywords: Adsorption; Modified sugarcane bagasse; Polyamines; Isotherm; Heavy metals

\section{Introduction}

Water pollution is a major environmental problem faced by modern society (Baird, 1995) that leads to ecological disequilibrium and health hazards (Kelter et al., 1997). Heavy metal ions such as copper, cadmium, lead, nickel, and chromium, often found in industrial wastewater, present acute toxicity to aquatic and terrestrial life, including humans. Thus, the discharge of effluents into the environment is a chief concern. The methods commonly used to remove toxic heavy metal from municipal and industrial wastewater are based on the adsorption of ions onto insoluble compounds and the separation of the sediments formed. Many efforts have been made recently to

\footnotetext{
* Corresponding author. Tel.: +55 3135591717; fax: +55315511707.

E-mail address: laurent@iceb.ufop.br (L.F. Gil).
}

find cheaper pollution control methods and materials (Panday et al., 1985; Ali and Bishtawi, 1997; Acemioğlu and Alma, 2001).

The new material world trends point to the importance of using industrial and agricultural residues as production starting materials. Reusing and recycling these residues can minimize the environmental problems associated with their build-up and reduce the use of noble starting materials. This trend has contributed to the reconsideration of the use of traditional biomaterials such as natural lignocellulosic fibers to substitute synthetic polymers, for example, since in many cases they have a better performance.

Brazil is the world leading producer of sugarcane for both the alcohol and the sugar industries. These industries produce a large amount of sugarcane bagasse and although it is burned to produce energy for sugar mills, leftovers are still significant. Thus, on account of the importance of 
bagasse sugar as an industrial waste, there is a great interest in developing chemical methods for recycling it. Sugarcane bagasse has around $50 \%$ cellulose, $27 \%$ polyoses, and $23 \%$ lignin (Caraschi et al., 1996). These three biological polymers have many hydroxyl and/or phenolic functions that can be chemically reacted to produce materials with new properties (Xiao et al., 2001; Navarro et al., 1996).

Despite the many studies of the chemical modification of cellulose published around the world in this area (Gurnani et al., 2003; Gellerested and Gatenholm, 1999), only a few have investigated the modification of bagasse sugar (Krishnan and Anirudhan, 2002; Orlando et al., 2002).

This work describes the preparation and the evaluation of new chelating materials from sugarcane bagasse to adsorb heavy metal ions in aqueous solution. In a preliminary study, it has been chosen to study the adsorption of $\mathrm{Cu}^{2+}, \mathrm{Cd}^{2+}$, and $\mathrm{Pb}^{2+}$. The first part of this work describes the modification of sugarcane bagasse with succinic anhydride to introduce carboxylic functions to sugarcane bagasse and the chemical introduction of commercial linear polyamine via the formation of amide functions. It is well known that polyamines have powerful chelating properties, mainly towards ions such as $\mathrm{Cu}^{2+}, \mathrm{Zn}^{2+}$, and $\mathrm{Pb}^{2+}$ (Bianchi et al., 1991; Martell and Hancock, 1996).

The second part of this work evaluates the adsorption of $\mathrm{Cu}^{2+}, \mathrm{Cd}^{2+}$, and $\mathrm{Pb}^{2+}$ onto three modified sugarcane bagasses (MSBs) from aqueous single metal ion solutions by classical titration. The results were analyzed by the Langmuir and Freundlich models (Ho et al., 2005).

\section{Methods}

\subsection{Materials}

Polyamines ethylenediamine $\mathbf{3}$ and triethylenetetramine 4 were used in this work. Succinic anhydride, 1,3-diisopropylcarbodiimide (DIC), and triethylenetetramine, from Aldrich, were used without purification. Ethylenediamine and dimethylformamide were distilled before use. Pyridine was refluxed with $\mathrm{NaOH}$ and distilled.

\subsection{Sugarcane bagasse preparation}

Sugarcane bagasse was dried at $100^{\circ} \mathrm{C}$ in an oven for approximately $24 \mathrm{~h}$ and next fiber size was reduced to powder by milling with tungsten ring. The resulting material was sieved with a 4-sieve system $(10,30,45$, and 60 mesh). Then, the material was washed with distilled water under stirring at $65^{\circ} \mathrm{C}$ for $1 \mathrm{~h}$ and dried at $100^{\circ} \mathrm{C}$. Finally, it was washed anew in a sohxlet system with n-hexane/ ethanol (1:1) as solvent for $4 \mathrm{~h}$.

\subsection{Synthesis of MSBs 1 and 2}

Washed and dried sugarcane bagasse $(5.02 \mathrm{~g})$ was treated with succinic anhydride (12.56 g) under pyridine reflux $(120 \mathrm{~mL})$ for $18 \mathrm{~h}$. The solid material was filtered, washed in sequence with $1 \mathrm{M}$ solution of acetic acid in $\mathrm{CH}_{2} \mathrm{Cl}_{2}$, $0.1 \mathrm{M}$ solution of $\mathrm{HCl}$, ethanol $95 \%$, distilled water, and finally with ethanol $95 \%$. After drying at $100^{\circ} \mathrm{C}$ in an oven for $30 \mathrm{~min}$ and in a desiccator overnight, MSB 1 (7.699 g) was obtained with a mass gain of $53.4 \%$. MSB 2 was obtained by treatment of 1 with saturated $\mathrm{NaHCO}_{3}$ solution for $30 \mathrm{~min}$ and afterwards by filtering using sintered filter and washing with distilled water and ethanol.

\subsection{Synthesis of MSBs 5 and $\mathbf{6}$}

The process used to introduce amine functions was the same as that used to prepare MSB 5 and 6. MSB 1 was treated with 5 equiv of 1,3-diisopropylcarbodiimide (DIC) and 6 equiv of polyamine in anhydrous DMF at room temperature for $22 \mathrm{~h}$ under stirring. After filtration, the materials were washed with DMF, a saturated solution of $\mathrm{NaHCO}_{3}$, distilled water, and finally with ethanol. Next, they were dried at $80^{\circ} \mathrm{C}$ in an oven for $30 \mathrm{~min}$ and in a desiccator overnight.

\subsection{Kinetic study of metal ion adsorption of MSBs 2, 5 , and 6}

Experiments with each material and metal ion were performed to determine the adsorption equilibrium time from 10 to $90 \mathrm{~min}$ in $10 \mathrm{~min}$ intervals. The amount of $100 \mathrm{mg}$ MSB was placed in a $250-\mathrm{mL}$ Erlenmeyer with $100.0 \mathrm{~mL}$ metal ion solution with concentration of $200 \mathrm{mg} / \mathrm{L}$ under stirring. The experiments were done at $\mathrm{pHs} 5.8$ for $\mathrm{Cu}^{2+}$, 7.0 for $\mathrm{Cd}^{2+}$, and 6.2 for $\mathrm{Pb}^{2+}$, optimal values to obtain the best adsorption. To adjust $\mathrm{pH}$ values, was added $\mathrm{NaOH}$ solution $(0.01 \mathrm{~mol} / \mathrm{L})$ into metal solutions with MSB. After filtration, metal ion concentration was determined by EDTA titration.

\section{6. $p H$ study of metal ion adsorption of MSBs 2, 5, and $\mathbf{6}$}

Experiments with each material and metal ion were performed to determine the effect of $\mathrm{pH}$ on ion adsorption. An amount of $100 \mathrm{mg}$ MSB was placed into a $250-\mathrm{mL}$ Erlenmeyer with $100.0 \mathrm{~mL}$ of metal ion solution $200 \mathrm{mg} / \mathrm{L}$ under stirring. $\mathrm{pH}$ was calibrated with $\mathrm{HCl}$ or $\mathrm{NaOH}$ solutions $(0.1-1.0 \mathrm{~mol} / \mathrm{L})$. The reaction times used were $30 \mathrm{~min}$ (MSB 2) or $40 \mathrm{~min}$ (MSB 5 and 6) for $\mathrm{Cu}^{2+}$ and $\mathrm{Cd}^{2+}$, and 40 min (MSB 2) or 50 min (MSB 5 and 6) for $\mathrm{Pb}^{2+}$. Metal ion concentration was determined after filtration by EDTA titration. No significative variation of $\mathrm{pH}$ was observed at the end of each experiment.

\subsection{Adsorption isotherms of MSBs 2, 5, and $\mathbf{6}$}

Experiments were performed for each material and metal ion to determine adsorption isotherms. In each experiment, $100 \mathrm{mg}$ of MSB was placed into a $250-\mathrm{mL}$ Erlenmeyer with $100.0 \mathrm{~mL}$ of metal ion solution in specific concentrations (between $200 \mathrm{mg} / \mathrm{L}$ and $400 \mathrm{mg} / \mathrm{L}$ ) under stirring. Each experiment was performed at the $\mathrm{pH}$ of 
larger ion adsorption during the time necessary for equilibrium (Tables 3 and 4). After filtration, the metal ion concentration was determined by EDTA titration.

\subsection{Characterization of the new obtained materials}

MSB 1, 2, 5, and $\mathbf{6}$ were characterized by IR spectroscopy in a Nicolet Impact 410 equipment with $\mathrm{KBr}$. Elemental analyses were accomplished in Analyzer 2400 CHNS/O Perkin Elemer Series II.

\section{Results and discussion}

\subsection{Synthesis of MSBS 1, 2, 5, and 6}

The synthesis route used to prepare MSBs 1, 2, 5, and 6 are presented in Scheme 1. Prewashed sugarcane bagasse was succinylated for various periods of time. The degree of succinylation of the bagasse fibers was determined by measuring the quantity of acid function. The results are shown in Fig. 1. The concentration of carboxylic functions per mg of bagasse was determined by retro titration. For this, MSB 1 was initially treated with an excess solution of $\mathrm{NaOH}(0.01 \mathrm{~mol} / \mathrm{L})$ for $30 \mathrm{~min}$. Soon afterwards the material was filtered and the obtained solution was titrated with an $\mathrm{HCl}$ solution $(0.01 \mathrm{~mol} / \mathrm{L})$. The highest degree of succinylation was reached after 18 -h reaction. Using this reaction time, sugarcane bagasse was succinylated to produce MSB 1, which presented a weight gain of 54\% and a concentration of carboxylic acid function per $\mathrm{mg}$ of $3.83 \times 10^{-6} \mathrm{~mol}$. Next, MSB 1 was treated with a saturated $\mathrm{NaHCO}_{3}$ solution to produce MSB 2.

Starting from MSB 1, two polyamines were introduced: ethylenediamine 3 and triethylenetetramine 4 . The method-

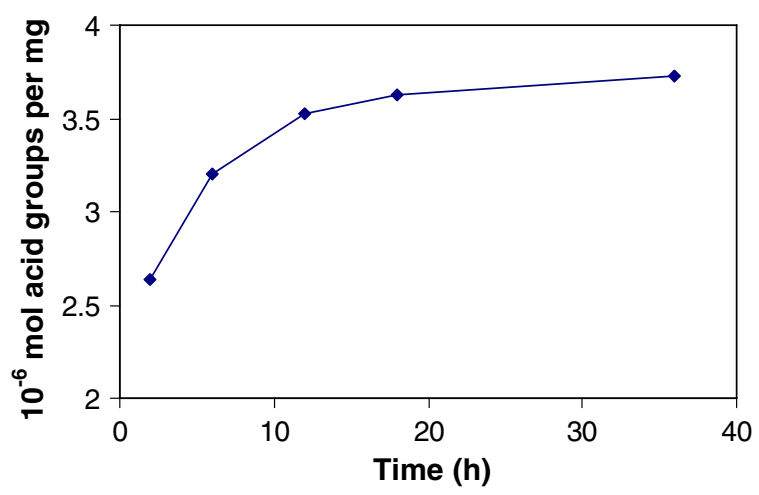

Fig. 1. Quantity of acid function as a function of succinic anhydride treatment time.

ology used to introduce the polyamines was the same for the two MSBs 5 and $\mathbf{6}$, as shown in Scheme 1. Concentrations of $2.4 \times 10^{-6} \mathrm{~mol}(5)$ and $2.6 \times 10^{-6} \mathrm{~mol} \mathrm{(6)}$ of amine function per $\mathrm{mg}$ of material were determined by back titration with excess $\mathrm{HCl}$ solution. The introduction of the amine functions was also verified by IR spectroscopy (Table 1) and elemental analysis (Table 2).

\subsection{Characterization of MSBs $\mathbf{1}, \mathbf{5}$, and $\mathbf{6}$}

Characterization of carboxylated MSB 1 was accomplished by IR spectroscopy. The spectrum of unmodified sugarcane bagasse and MSB 1 are presented in Fig. 2. The spectrum of MSB 1 displayed two strong bands at 1740 and $1726 \mathrm{~cm}^{-1}$ in relation to that of unmodified sugarcane bagasse. This demonstrated the presence of two types of carbonyl functions, one relative to carboxylic acid and another relative to the ester. The acid and ester IR bands indicate that succinic anhydride acylated the

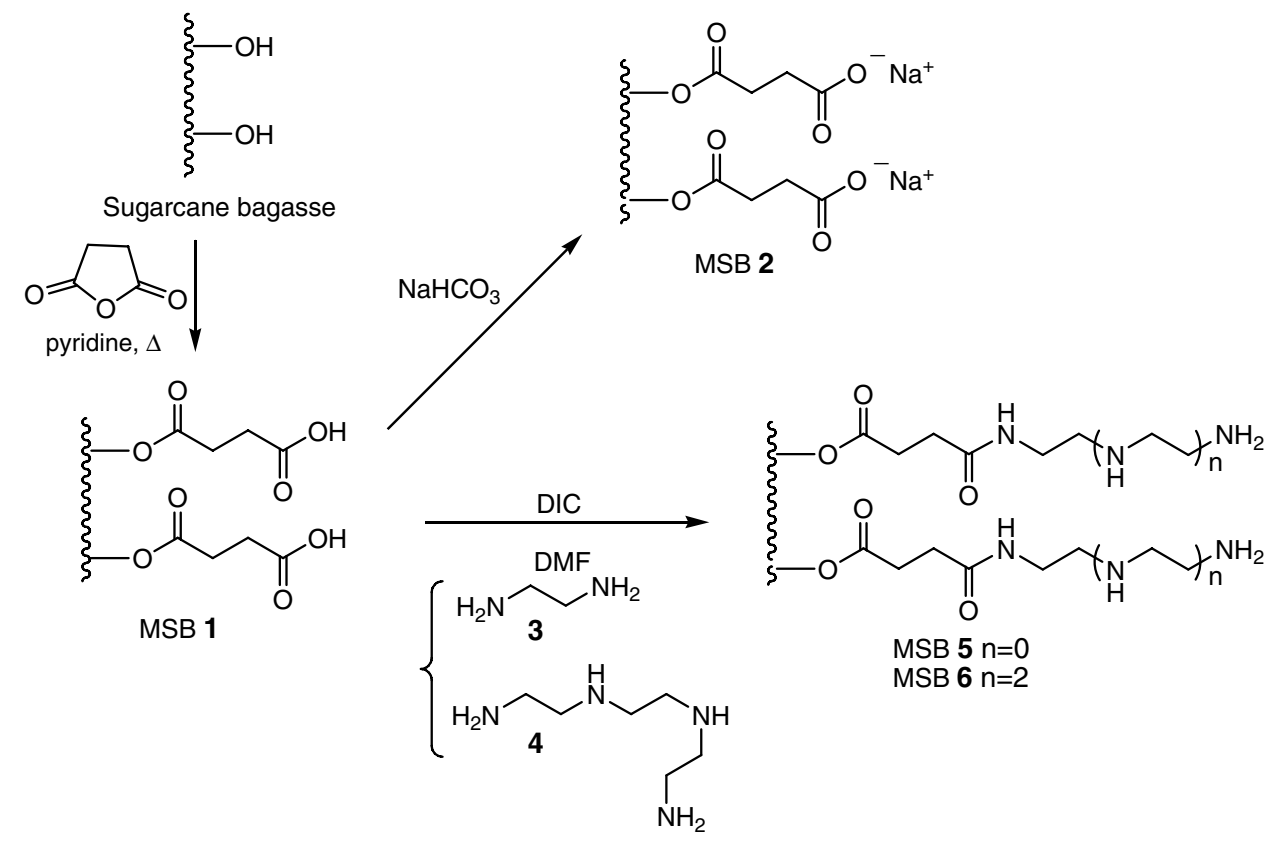

Scheme 1. Synthesis route used to obtain MSBs 1, 2, 5, and 6. 
Table 1

Main IR spectrum bands observed in MSBs 1, 5, and 6

\begin{tabular}{ll}
\hline MSB & Main bands observed $\left(\mathrm{cm}^{-1}\right)$ \\
\hline $\mathbf{1}$ & 1740,1726 \\
$\mathbf{5}$ & $1745,1650,1635,1575,1423,1060$ \\
$\mathbf{6}$ & $1738,1651,1635,1560,1400,1159,1060$ \\
\hline
\end{tabular}

Table 2

Elemental analysis of MSBs 1, 2, 5, and $\mathbf{6}$

\begin{tabular}{llll}
\hline & $\mathrm{C}(\%)$ & $\mathrm{H}(\%)$ & $\mathrm{N}(\%)$ \\
\hline Sugarcane bagasse & 43.98 & 6.02 & 0.13 \\
MSB 1 & 45.41 & 5.62 & 0.10 \\
MSB 2 & 38.04 & 5.14 & 0.01 \\
MSB 5 & 44.01 & 6.51 & 2.21 \\
MSB 6 & 46.88 & 6.65 & 3.43 \\
\hline
\end{tabular}

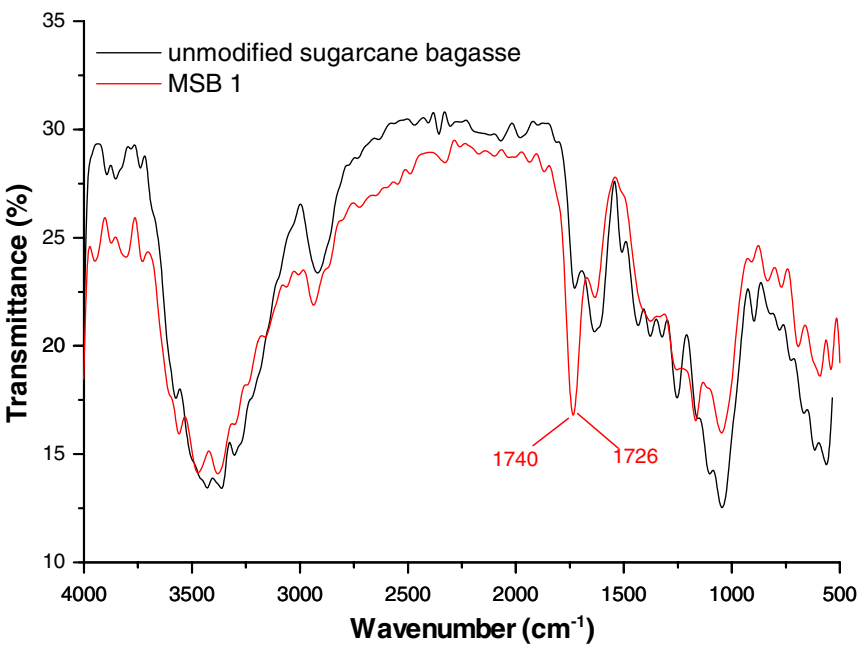

Fig. 2. IR spectrum (KBr) of unmodified sugarcane bagasse and MSB $\mathbf{1}$.

hydroxy group of bagasse to generate an ester bond with consequent release of a carboxylic acid functional group.

The spectra of MSBs 5 and $\mathbf{6}$ (Figs. 3 and 4, respectively) showed three new strong bands at $1550-1650 \mathrm{~cm}^{-1}$ (see data in Table 1) corresponding to the presence of amide and amine functions, and one band at $1060 \mathrm{~cm}^{-1}$ corresponding to $\mathrm{C}-\mathrm{N}$ stretch. The bands at 1635 and $1650 \mathrm{~cm}^{-1}$ (Fig. 3) correspond to the axial deformation of the carbonyl of the amide function and the angular deformation of the $\mathrm{N}-\mathrm{H}$ bond of the amine function. The band at $1575 \mathrm{~cm}^{-1}$ corresponds to the angular deformation of the $\mathrm{N}-\mathrm{H}$ bond of the amide function. The band at $1159 \mathrm{~cm}^{-1}$ (Fig. 4) corresponds to the asymmetric stretch of $\mathrm{C}-\mathrm{N}-\mathrm{C}$ bond.

The main bands observed in all MSBs are presented in Table 1.

MSB elemental analysis data presented in Table 2 show a modification in the carbon and hydrogen composition of MSB 1 and a larger proportion of nitrogen as the number of amine functions in the used polyamine increases.

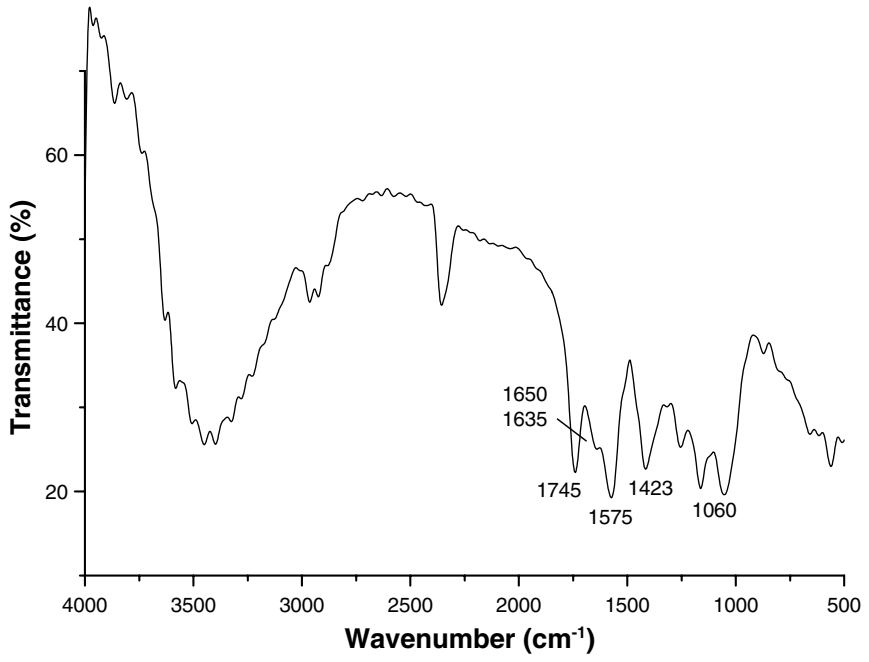

Fig. 3. IR spectrum $(\mathrm{KBr})$ of MSB 5.

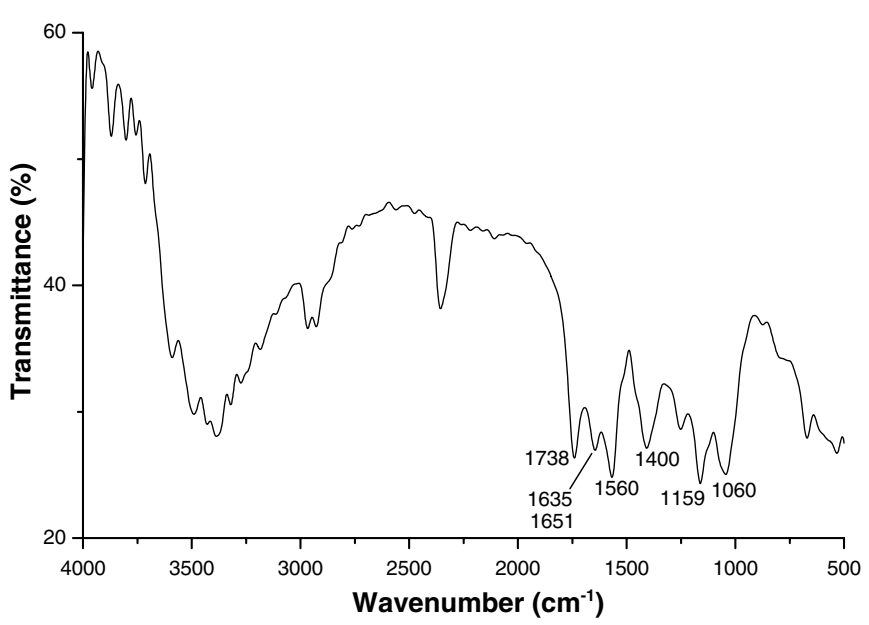

Fig. 4. IR spectrum $(\mathrm{KBr})$ of MSB 6.

\subsection{Study of adsorption of $\mathrm{Cu}^{2+}, \mathrm{Cd}^{2+}$ and $\mathrm{Pb}^{2+}$ on $M S B S 2,5$, and 6}

The study of the MSB adsorption properties was accomplished for each material and metal ion. A kinetic study and an adsorption study as a function of $\mathrm{pH}$ were first carried out.

\subsubsection{Effect of contact time}

The kinetic study of MSB 2 with $\mathrm{Cu}^{2+}, \mathrm{Cd}^{2+}$, and $\mathrm{Pb}^{2+}$ ions in aqueous solution is presented in Fig. 5. Adsorption equilibrium was reached after $20 \mathrm{~min}$ for $\mathrm{Cd}^{2+}$ ions. A time of 30 min was chosen for all studies of MSB 2 with $\mathrm{Cd}^{2+}$. The adsorption equilibrium times chosen for $\mathrm{pH}$ and concentration dependent experiments are presented in Table 3.

Similar studies were accomplished for MSBs 5 and $\mathbf{6}$ for $\mathrm{Cu}^{2+}, \mathrm{Cd}^{2+}$, and $\mathrm{Pb}^{2+}$. The results are presented in Table 3 .

\subsection{2. $p H$ Effect}

The removal of metal ions from aqueous solutions by adsorption is dependent on solution $\mathrm{pH}$ as it affects adsor- 


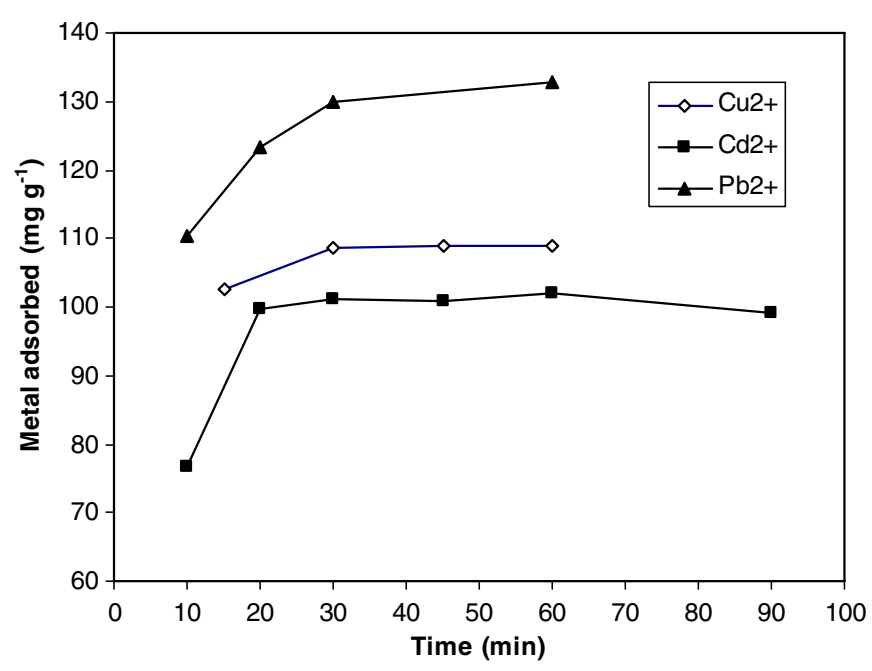

Fig. 5. Effect of contact time on MSB 2 metal ion adsorption.

Table 3

Adsorption equilibrium times of MSBs 2, 5 and $\mathbf{6}$

\begin{tabular}{llll}
\hline MSB & \multicolumn{2}{l}{ Equilibrium time $(\min )$} & $\mathrm{Pb}^{2+}$ \\
\cline { 2 - 4 } & $\mathrm{Cu}^{2+}$ & $\mathrm{Cd}^{2+}$ & 40 \\
$\mathbf{2}$ & 30 & 30 & 50 \\
$\mathbf{5}$ & 40 & 40 & 50 \\
$\mathbf{6}$ & 40 & 40 & \\
\hline
\end{tabular}

bent surface charge, the degree of ionization, and the species of adsorbates. The study of adsorption of $\mathrm{Cd}^{2+}$, $\mathrm{Cd}^{2+}$, and $\mathrm{Pb}^{2+}$ on MSB 2 as a function of $\mathrm{pH}$ was accomplished with the reaction times given in Table 3; the results are presented in Fig. 6. The adsorption of the three metal ions increases with the increase in $\mathrm{pH}$. Maximum removal of $\mathrm{Cd}^{2+}$ was observed above $\mathrm{pH} 6$ and in the case of $\mathrm{Pb}^{2+}$ and $\mathrm{Cu}^{2}$, above $\mathrm{pH} 5$ and 5.5.

Similar studies were accomplished for MSBs 5 and $\mathbf{6}$ and $\mathrm{Cu}^{2+}, \mathrm{Cd}^{2+}$ and $\mathrm{Pb}^{2+}$ with similar results, as shown in Table 4.

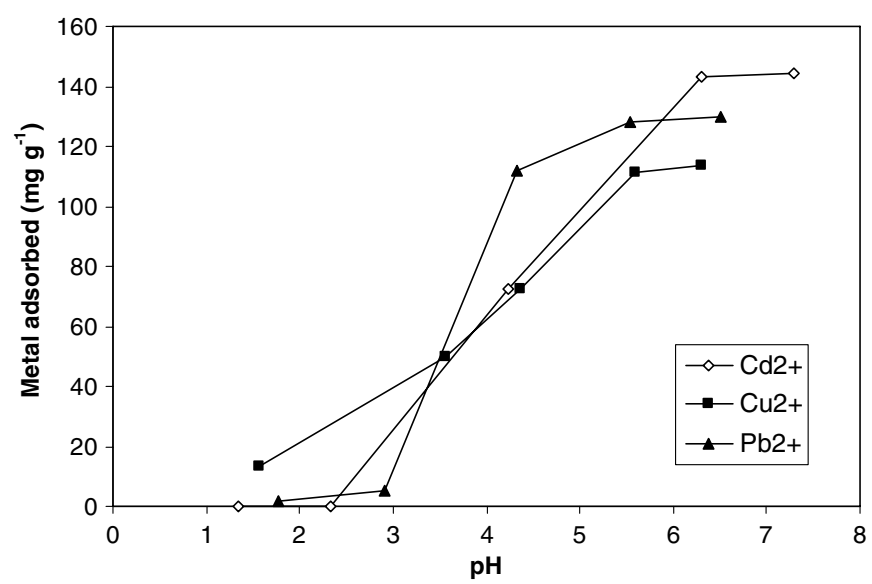

Fig. 6. Adsorption of metal ions on MSB 2 as a function of $\mathrm{pH}$.
Table 4

$\mathrm{pH}$ of largest adsorption of MSBs $\mathbf{2 , 5}$ and $\mathbf{6}$

\begin{tabular}{llll}
\hline MSB & \multicolumn{3}{l}{$\mathrm{pH}$ of largest adsorption } \\
\cline { 2 - 4 } & $\mathrm{Cu}^{2+}$ & $\mathrm{Cd}^{2+}$ & $\mathrm{Pb}^{2+}$ \\
\hline $\mathbf{2}$ & $5.5-6.0$ & $6.5-7.5$ & $5.0-6.0$ \\
$\mathbf{5}$ & $5.5-6.0$ & $6.5-7.5$ & $5.0-6.0$ \\
$\mathbf{6}$ & $5.5-6.0$ & $6.5-7.5$ & $5.0-6.0$ \\
\hline
\end{tabular}

\subsubsection{Adsorption isotherms}

The Langmuir (Ho et al., 2005) (Eq. (1)) and Freundlich (Eq. (2)) isotherms were evaluated by adsorption experiments as a function of the initial metal ion concentrations in aqueous solution under equilibrium time and $\mathrm{pH}$ conditions given in Tables 3 and 4 . The results of each material and metal ion are presented in Fig. 7 (Langmuir) and Fig. 8 (Freundlich) and Table 5.

$\frac{c}{q}=\frac{1}{Q_{\max } \times b}+\frac{c}{Q_{\max }}$

$\ln q=\ln k+\frac{1}{n} \ln c$
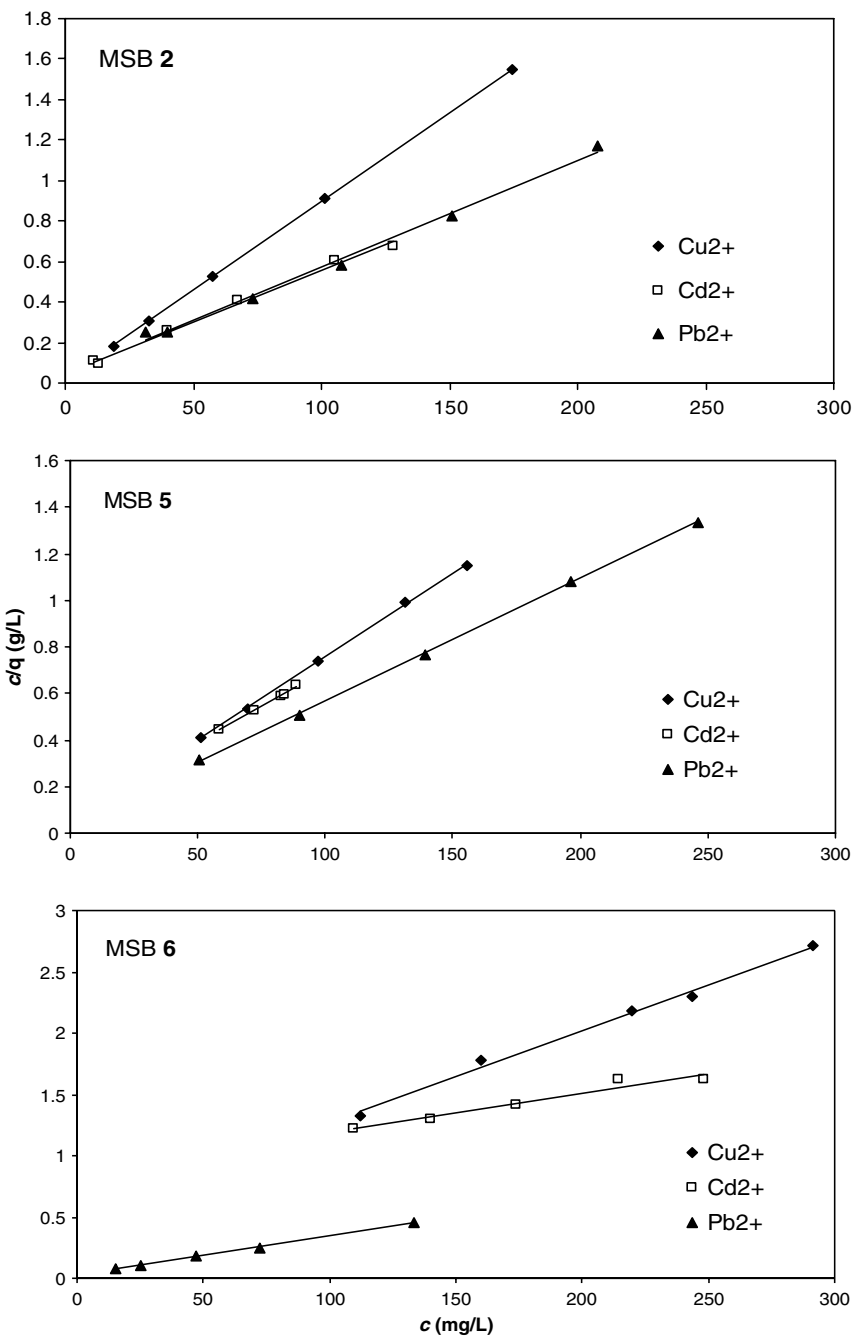

Fig. 7. The Langmuir isotherms of MSBs 2, 5, and $\mathbf{6}$. 

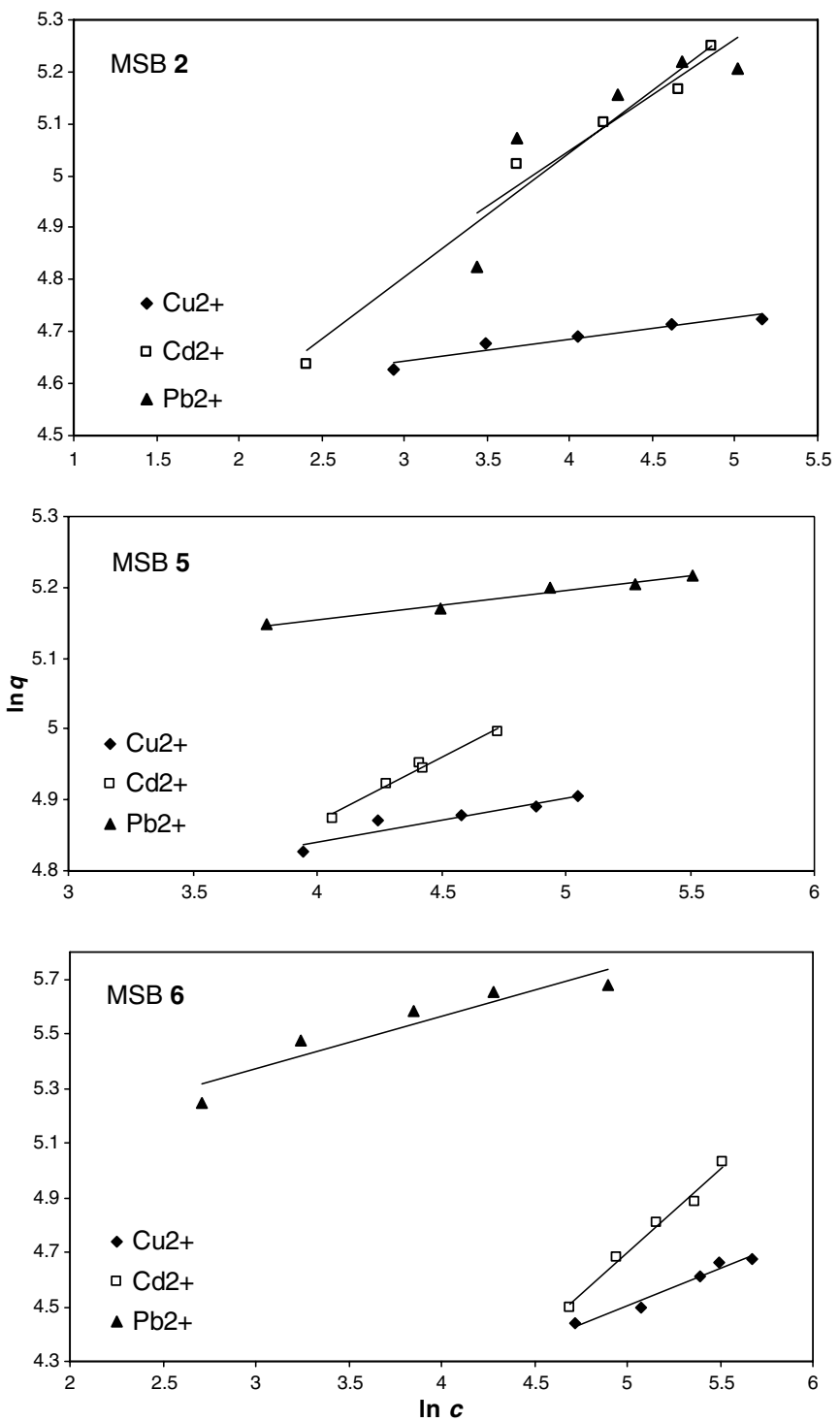

Fig. 8. The Freundlich isotherms of MSBs 2, 5, and $\mathbf{6}$.

Table 5

The Langmuir and Freundlich parameters for $\mathrm{Cu}^{2+}, \mathrm{Cd}^{2+}$ and $\mathrm{Pb}^{2+}$ adsorption

\begin{tabular}{|c|c|c|c|c|c|c|c|}
\hline \multirow[t]{2}{*}{ Metalion } & \multirow[t]{2}{*}{ MSB } & \multicolumn{3}{|c|}{ Langmuir } & \multicolumn{3}{|c|}{ Freundlich } \\
\hline & & $\begin{array}{l}Q_{\max } \\
(\mathrm{mg} / \mathrm{g})\end{array}$ & $\begin{array}{l}b \\
(\mathrm{~L} / \mathrm{mg})\end{array}$ & $r^{2}$ & $\begin{array}{l}k \\
(\mathrm{mg} / \mathrm{g})\end{array}$ & $n$ & $r^{2}$ \\
\hline \multirow[t]{3}{*}{$\mathrm{Cu}^{2+}$} & 2 & 114 & 0.431 & 1 & 91.6 & 23.9 & 0.9193 \\
\hline & 5 & 139 & 0.173 & 0.9998 & 98.3 & 15.8 & 0.9061 \\
\hline & 6 & 133 & 0.014 & 0.9927 & 22.8 & 3.64 & 0.9635 \\
\hline \multirow[t]{3}{*}{$\mathrm{Cd}^{2+}$} & 2 & 196 & 0.103 & 0.9934 & 59.4 & 4.16 & 0.9773 \\
\hline & 5 & 164 & 0.068 & 0.9957 & 62.8 & 5.49 & 0.9834 \\
\hline & 6 & 313 & 0.004 & 0.9528 & 5.15 & 1.63 & 0.9856 \\
\hline \multirow[t]{3}{*}{$\mathrm{Pb}^{2+}$} & 2 & 189 & 0.110 & 0.9945 & 66.0 & 4.66 & 0.7579 \\
\hline & 5 & 189 & 0.125 & 0.9999 & 147 & 24.51 & 0.981 \\
\hline & 6 & 313 & 0.121 & 0.9994 & 121 & 5.21 & 0.877 \\
\hline
\end{tabular}

where $q(\mathrm{mg} / \mathrm{g})$ is the concentration of adsorbed metal ions per gram of adsorbent, $c(\mathrm{mg} / \mathrm{L})$ is the concentration of metal ion in aqueous solution at equilibrium, $Q_{\max }$ and $b$ are the Langmuir equation parameters and $k$ and $n$ are the Freundlich equation parameters.

High correlation coefficients of linearized Langmuir and Freundlich equations indicate that these models can explain metal ion adsorption by the materials satisfactorily. Therefore, both models explained metal ion adsorption by MSBs 2, 5, and $\mathbf{6}$ as can be observed in Table 5, with the exception of the Freundlich model for $\mathrm{Pb}^{2+}$ adsorption by MSB 2.

The Langmuir isotherm parameter $Q_{\max }$ indicates the maximum adsorption capacity of the material, in other words, the adsorption of metal ions at high concentrations. It can be observed in Table 5 that MSB 5 presents the largest $\mathrm{Cu}^{2+}$ adsorption capacity while MSB 6 adsorbs $\mathrm{Cd}^{2+}$ and $\mathrm{Pb}^{2+}$ the best. Langmuir parameter $b$ indicates the bond energy of the complexation reaction of the material with the metal ion. It can be observed that MSB 2 presents the largest bond energy for $\mathrm{Cu}^{2+}$ and $\mathrm{Cd}^{2+}$, while three materials do not differ significantly for $\mathrm{Pb}^{2}$.

The Freundlich isotherm parameter $k$ indicates the adsorption capacity when the concentration of the metal ion in equilibrium is unitary, in our case $1 \mathrm{mg} / \mathrm{L}$. This parameter is useful in the evaluation of the adsorption capacity of metal ions in dilute solutions, a case closer to the characteristics of industrial effluents. The values of $k$ of MSB 2 and 5 are much similar for $\mathrm{Cu}^{2+}$ and $\mathrm{Cd}^{2+}$ and much higher than that for MSB 6. This shows the superiority of both materials in the adsorption of these metal ions in low concentrations. MSB 5 has a higher $k$ value for $\mathrm{Pb}^{2+}$ when compared to those of the other materials.

These results were compared with those of Vaughan et al. (2001) for a commercial macroreticular chelating resin with thiol functional groups, Duolite GT-73. The $Q_{\max }$ of Duolite GT-73 for $\mathrm{Cu}^{2+}, \mathrm{Cd}^{2+}$, and $\mathrm{Pb}^{2+}$ were $62 \mathrm{mg} / \mathrm{g}, 106 \mathrm{mg} / \mathrm{g}$, and $122 \mathrm{mg} / \mathrm{g}$, respectively. Duolite GT-73 exhibited $Q_{\max }$ lower than those of MSBs (Table 5).

\section{Conclusions}

Through a fast, effective, and cheap methodology, it was possible to devise a strategy to introduce chelating functions (carboxylic acid and amine) to sugarcane bagasse. Modified sugarcane bagasses presented a good adsorption capacity for $\mathrm{Cu}^{2+}, \mathrm{Cd}^{2+}$, and $\mathrm{Pb}^{2+}$ ions with maximum adsorption capacity observed for MSB 6. It has been demonstrated that metal ion adsorption efficiency is proportional to the number of amine functions introduced into the material. MSB 2, which contained only carboxylate functions, showed an efficiency similar to that of MSB 5, a material of much more complex synthesis.

\section{Acknowledgements}

We thank FAPEMIG for financial support, CAPES and UFOP. 


\section{References}

Acemioğlu, B., Alma, M.H., 2001. Equilibrium studies on adsorption of $\mathrm{Cu}(\mathrm{II})$ from aqueous solution onto cellulose. Journal of Colloid and Interface Science 243, 81-83.

Ali, A.A., Bishtawi, R., 1997. Removal of lead and nickel ions using zeolite tuff. Journal of Chemical Technology and Biotechnology 69, 27-34.

Baird, C., 1995. Environmental Chemistry. W.H. Freeman and Company, New York.

Bianchi, A., Micheloni, M., Paoletti, P., 1991. Thermodynamic aspects of the polyazacycloalkane complexes with cations and anions. Coordination Chemistry Reviews 110, 17-113.

Caraschi, J.C., Campana, S.P., Curvelo, A.A.S., 1996. Preparação e Caracterização de Polpas Obtidas a Partir de Bagaço de Cana de Açúcar. Polímeros: Ciência e Tecnologia 3, 24-29.

Gellerested, F., Gatenholm, P., 1999. Surface properties of lignocellulosic fibers bearing carboxylic groups. Cellulose 6, 103-121.

Gurnani, V., Singh, A.K., Venkataramani, B., 2003. 2,3-Dihydroxypyridine-loaded cellulose: a new macromolecular chelator for metal enrichment prior to their determination by atomic absorption spectrometry. Analytical and Bioanalytical Chemistry 377, 1079-1086.

Ho, Y.S., Chiu, W.T., Wang, C.C., 2005. Regression analysis for the sorption isotherms of basic dyes on sugarcane dust. Bioresource Technology 96, 1285-1291.
Kelter, P.B., Grundman, J., Hage, D.S., Carr, J.D., Castro-Acuña, C.M., 1997. A discussion of water pollution in the United States and Mexico; with High School Laboratory Activities for the analysis of lead, atrazine, and nitrate. Journal of Chemical Education 74, 1413-1421.

Krishnan, K.A., Anirudhan, T.S., 2002. Removal of mercury(II) from aqueous solutions and chlor-alkali industry effluent by steam activated and sulphurised activated carbons prepared from bagasse pith: kinetics and equilibrium studies. Journal of Hazardous Materials 92, 161-183.

Martell, A.E., Hancock, R.D., 1996. Metal complexes in aqueous solutions. Plenum, New York.

Navarro, R.R., Sumi, K., Fujii, N., Matsumura, M., 1996. Mercury removal from wastewater using porous cellulose carrier modified with polyethyleneimine. Water Research 30, 2488-2494.

Orlando, U.S., Baes, A.U., Nishijima, W., Okada, M., 2002. Preparation of chelating agents from sugarcane bagasse by microwave radiation as an alternative ecologically benign procedure. Green Chemistry 4, 555557.

Panday, K.K., Gur, P., Singh, V.N., 1985. Copper(II) removal from aqueous solutions by fly ash. Water Research 19, 869-873.

Vaughan, T., Seo, C.W., Marshall, W.E., 2001. Removal of selected metal ions from aqueous solution using modified corncobs. Bioresource Technology 78, 133-139.

Xiao, B., Sun, X.F., Sun, R., 2001. The chemical modification of lignins with succinic anhydride in aqueous systems. Polymer Degradation and Stability 71, 223-231. 